\title{
A Construção Social da Qualidade na Microrregião do Vale dos Vinhedos
}

\author{
Gisele Trindade Molinari ${ }^{1}$ e Antônio Domingos Padula ${ }^{2}$
}

Resumo: A qualidade é uma questão complexa que se manifesta com veemência no Vale dos Vinhedos, principal área produtora de vinhos finos no Brasil. A pesquisa, então, versa sobre a construção social em torno da qualidade dos vinhos finos na microrregião, a qual foi demarcada para iniciar um processo de reconhecimento de Indicações Geográficas. Cada vez mais os mercados são percebidos como construções sociais, em que os atores são capazes de criar produtos diferenciados. Nesse sentido, o objetivo do estudo centra-se na caracterização e na análise do Vale dos Vinhedos como um ambiente institucional e organizacional construído socialmente, com base em elementos da coordenação dos agentes. Apoiado em metodologia de caráter exploratório com enfoque qualitativo, aplicando-se entrevistas semiestruturadas a agentes selecionados, os resultados discutidos levaram à observação de que a construção social promoveu evolução da qualidade e desenvolvimento, assim que atores buscam revelar e afirmar uma identidade.

Palavras-chaves: vinhos finos, qualidade, coordenação dos agentes.

Abstract: The quality is a complex issue that manifests significantly in Vale dos Vinhedos, the main producing area of fine wines in Brazil. Therefore, the study discusses the social construction of the quality of fine wines in Vale dos Vinhedos, microregion that was defined to begin a process of recognition of Geographical Indication. Increasingly, markets have been perceived as social constructions, in which the actors have the ability to create differentiated products. The objective of this research is to characterize and analyze Vale dos Vinhedos as an institutional and organizational environment that is socially constructed, based on elements of the coordination of agents. A study was conducted with exploratory qualitative approach through interviews with selected agents. The result showed that social construction promotes quality evolution and development, when actors aimed to reveal and assert an identity.

Key-words: fine wines, quality, coordination of agents.

Classificação JEL: O43, Q13, R11, Z13.

\footnotetext{
1 Mestre em Agronegócios (UFRGS). E-mail: giselemolinari@rocketmail.com

2 Professor Dr. do programa de pós-graduação em Agronegócios (UFRGS). E-mail: adpadula@ea.ufrgs.br
} 


\section{Introdução}

A atividade vitivinícola é de relevância econômica para muitas regiões no mundo, todavia, a viticultura e a vinicultura também exercem valores sociais e culturais. De modo geral, o desenvolvimento da vitivinicultura liga-se a um contexto econômico, social, cultural, histórico, humano e ambiental.

Uma questão multifacetada de atenção à sociedade é a qualidade dos produtos que ela consome. A qualidade dos alimentos, no caso, envolve percepções objetivas e subjetivas. Diz respeito à conformidade com exigências de segurança alimentar e de sanidade, às propriedades organolépticas como cor, sabor e aspecto olfativo, ao valor nutricional, aos benefícios à saúde e, além disso, à apresentação do produto.

Conforme Trombin, Caldeira e Neves (2007), a globalização dos mercados junto à grande quantidade de informações disponibilizadas moldam um tipo de consumidor mais conscientizado e informado, que passa a se preocupar mais com a qualidade, a origem e a maneira como os produtos são fabricados. Nesse aspecto, o consumidor mostra-se um agente ativo, sinalizando a cadeia produtiva a respeito de seus gostos, suas preferências e levando informação sobre o alimento que consome (ZYLBERSZTAJN e SCARE, 2003).

A qualidade, por fim, tem representado um elemento diferencial de competitividade para os produtores. $\mathrm{O}$ atendimento de requisitos de qualidade confere valor agregado aos produtos.
Dessa forma, a fim de reduzir a incerteza sobre a qualidade dos produtos, é que se faz conveniente o uso de marcas coletivas e de certificações para atestar as suas propriedades. A busca por Indicações Geográficas (IGs) enquadra-se dentre esses mecanismos, pois consiste em recurso que presta identificação de atributos de qualidade aos produtos e serviços, bem como tem a peculiaridade de se referir a um território específico de produção.

Nesse contexto, atualmente, o espaço produtivo brasileiro vem experimentando uma forma especial de enfrentamento do cenário globalizado e bastante competitivo. Tem emergido, assim, a valorização do território e da produção local que, além do ideal de desenvolvimento, também cerca a questão sobre qualidade.

Com relação ao território e setores produtivos específicos, infere-se a importância dos atores locais e da articulação entre eles em vista do fortalecimento de suas atividades produtivas e da atenção ao seu local de produção. Sob essa perspectiva, os mercados locais vêm sendo percebidos como construções sociais. Segundo Abramovay (2004), a compreensão disso se refere à subjetividade dos agentes econômicos, à diversidade e à história de suas formas de coordenação, às representações mentais a partir das quais se relacionam uns com os outros, à capacidade de obter e inspirar confiança, de negociar, fazer cumprir contratos, estabelecer e realizar direitos.

Logo, são atores econômicos e sociais que interagem para desenvolver seu setor produtivo 
e seu território. Estes atores encontram-se aproximados, construindo um mercado com diferenciais, em que o produto assume uma identidade dada pelas condições de seu local. Em vista disso, há uma coordenação nesse contexto e deve-se considerar que cada agente envolvido carrega consigo interesses e valores. Existe um ordenamento mobilizado por princípios em distintas formas de coordenação dos agentes.

$\mathrm{Na}$ microrregião do Vale dos Vinhedos, local singular de atividade da vitivinicultura no País, várias dessas questões mencionadas podem consagrar-se à análise. O segmento nacional de vinhos finos enfrenta concorrência acirrada com seus similares importados. Além disso, a tributação para o produto no Brasil é elevada, interferindo no resultado de um produto com preços mais competitivos. Ainda, este tipo de produto tem baixo consumo no mercado interno e, até há pouco tempo, não apresentava aceitação expressiva.

Assim, os vinhos finos são produtos desafiadores em termos de competitividadee de qualidade. Logo, em um momento de cenário desfavorável, produtores reagem e buscam alternativas para reestruturar o seu setor produtivo. Um fato marcante para o Vale dos Vinhedos foi a conquista da Indicação de Procedência, em 2002, junto ao Instituto Nacional de Propriedade Industrial (Inpi), consistindo-se na primeira indicação geográfica em uma região do Brasil. Mais recentemente, no início de 2011, a microrregião parte para a aquisição da Denominação de Origem Vale dos Vinhedos, com a publicação do pedido pelo Inpi. E, ao final de 2012, é concedida a Denominação de Origem para os seus vinhos finos.

Diante da perspectiva apresentada, considerando-se a construção social da qualidade dos vinhos finos no Vale dos Vinhedos, questiona-se quem são, como agem e como se relacionam os atores envolvidos com a construção deste produto neste local, tal como princípios presentes que qualificam esta coordenação. O objetivo é, então, caracterizar e analisar a microrregião do Vale dos Vinhedos como um ambiente institucional e organizacional construído socialmente, que sinaliza a qualidade do seu produto. Desse modo, a pesquisa empenha-se em buscar contribuir para o entendimento da construção social da qualidade no Vale dos Vinhedos, enfatizando as consequências positivas e os desafios.

\section{Fundamentação teórica}

Com o intuito de abordar e sustentar o tema de construção social da qualidade, empregado para a análise no Vale dos Vinhedos, a fundamentação teórica da pesquisa abrange a questão sobre qualidade e vale-se da Teoria das Convenções, a qual auxiliará no entendimento dos valores que processam a coordenação dos agentes, como forma de justificação da qualidade do seu produto.

\subsection{A questão da qualidade}

Cada vez mais a questão da qualidade dos produtos alimentares toma espaço, tanto por parte dos consumidores que prezam pela segurança alimentar e buscam determinados atributos de qualidade quanto pelo lado dos produtores que necessitam adequar-se às exigências técnicas $\mathrm{e}$ de mercado. A concepção da qualidade de um produto deve considerar a produção desde o setor primário até o industrial e ainda relevar as questões de distribuição, comercialização e demais serviços relacionados. De tal modo, a questão da qualidade representa um tema de caráter multi ou interdisciplinar, envolvendo diversas esferas. Já que envolve os segmentos de pesquisa, desenvolvimento e ensino, além da regulamentação e os investimentos necessários, também deve contar com o apoio de órgãos públicos (ZYLBERSZTAJN e SCARE, 2003).

Dessa forma, a qualidade tem se apresentado como elemento fundamental da dinâmica dos mercados, como aponta Flexor (2005), designando uma forma de diferenciação e de segmentação para as empresas em um ambiente competitivo e instável. Já para os consumidores, consiste em um conjunto de atributos e características que influenciam suas decisões de compra. Além disso, 
segundo o autor, a industrialização do sistema agroalimentar incentiva a criação de novos produtos por um lado; e, de outro, gera uma série de problemas associados a incertezas técnicas, organizacionais, humanas e financeiras.

A qualidade de um produto pode ser identificada de acordo com diversos atributos. Estes podem ser identificados conforme critérios de caráter mais objetivos ou também subjetivos. Ponte e Gibbon (2005) classificam esses atributos em função da facilidade com que podem ser mensurados, nesse caso, os padrões de qualidade que comunicam informações. Os autores denominam como atributos de pesquisa os que podem ser verificados no instante da transação, tal como a cor. Os atributos de experiência, por sua vez, são aqueles avaliados somente após a transação, como exemplo o sabor. E, por fim, os atributos de crédito que não podem ser objetivamente verificados logo são baseados na confiança.

Diante disso, atualmente os consumidores têm demandado produtos com qualidade elevada. Todavia, para que isso seja viabilizado, são necessários indicadores ou sinais de qualidade. Para Hocquette e Gigli (2005), a marca, em um sentido genérico, é o arquétipo de tais sinais. Assim como, para Zylbersztajn e Scare (2003), no caso de mercados complexos, em que compradores não podem verificar por si próprios o atendimento a padrões de qualidade desejada, torna-se necessária a certificação da presença de atributos específicos e desejados dos produtos, por meio de entidades independentes privadas ou públicas.

A respeito disso, justificam-se as circunstâncias das indicações geográficas, das marcas coletivas e das certificações, visto que asseguram a procedência de determinado produto e sinalizam sua qualidade ao consumidor e, ao mesmo tempo, conferem proteção e valor agregado ao produtor. Em tal situação, como ressalta Tibério, Cristóvão e Fragata (2001), a questão da qualidade sustenta-se em três pilares: construir a qualidade; atestar e garantir a qualidade; e dar a conhecer a qualidade aos consumidores.

Com base em Fávero (2010), as indicações geográficas indicam a origem do produto e/ou serviço que tenha uma determinada reputação e tenha ou não relação com fatores naturais e/ ou humanos. É, portanto, um nome geográfico que distingue um produto ou serviço de seus semelhantes ou afins, visto que apresenta características diferenciadas que podem ser atribuídas à sua origem geográfica, configurando nestes o reflexo de fatores naturais e humanos. Dentre as características naturais, podem ser citadas as geográficas (solo, vegetação), meteorológicas (mesoclima), e as características humanas, como o cultivo, tratamento, manufatura.

Na lei brasileira, existem duas espécies de IGs: a Indicação de Procedência (IP) e a Denominação de Origem (DO). A Indicação de Procedência é o nome geográfico que se tornou conhecido como centro de extração, produção ou fabricação de determinado produto ou prestação de determinado serviço. Já a Denominação de Origem é conceituada como o nome geográfico que designa produto ou serviço cujas qualidades ou características se devam exclusiva ou essencialmente ao meio geográfico, incluídos fatores naturais e humanos (FÁVERO, 2010).

\subsection{Teoria das convenções}

A Sociologia Econômica é definida, segundo Swedberg (2004), como a aplicação de ideias, conceitos e métodos sociológicos aos fenômenos econômicos. Historicamente, as ideias de sociologia econômica vêm sendo tratadas por estudiosos de economia, de sociologia e outros. Conforme Wilkinson (2002, p. 2):

A novidade da sociologia econômica é o seu projeto de explicar o funcionamento dos mercados a partir de uma abordagem de redes sociais. Os fundadores da sociologia ou eram, ao mesmo tempo, economistas (Marx, Pareto), ou ocupavam cátedras de economia (Weber), ou desenvolveram uma reflexão crítica sobre a teoria econômica como parte central da elaboração das suas teorias sociais (Durkheim). A importância de desenvolver uma sociologia econômica 
foi defendida também nos trabalhos do Economista Schumpeter.

Por construção social, em um sentido amplo, entende-se a interação entre os setores da sociedade civil e as políticas públicas. Assim, pode-se ter a valorização da comunidade, dos produtos e do território com base nas relações sociais, construídos pela coletividade envolvida. Nesse aspecto, há três elementos fundamentais das relações sociais, que são a sua estruturação, a sua funcionalidade e a sua configuração territorial. Dessa forma, os resultados dependem da capacidade de relacionamento, da coesão entre os elementos que fazem parte e dos fluxos de informação (SHERER-WARREN, 1998).

A abordagem da economia das convenções, segundo Eymard-Duvernay et al. (2003), reflete sobre as ciências econômica e sociológica, em que a perspectiva procura ultrapassar as fronteiras entre a economia e a sociologia para identificar um espaço comum em ambas e reconsiderar. Portanto, não ignora as contribuições originais dos campos de conhecimento, mas repensa o espaço comum entre as duas disciplinas.

Três questões principais são dominadas pela teoria convencionalista: a caracterização do agente e os motivos para ação, os mecanismos de coordenação das ações e o papel dos valores e dos bens comuns (EYMARD-DUVERNAY et al., 2003). Nesse sentido, o agente deve entender a situação e a ação dos outros, utilizando as convenções para coordenar. Leva-se em conta o ambiente em coordenação, os valores coletivos e os ativos comuns, de acordo com os autores. Nessa linguagem, encontra-se um importante componente das instituições.

$\mathrm{Na}$ teoria das convenções, as diferentes formas de ação coletiva são chamadas de grandeurs ou mundos. Cada mundo possui sua definição própria de bem comum, tal como cada um deles tem um princípio comum superior. A existência dos mundos deriva de um compromisso coerente de objetos e ações (BOLTANSKI e THÉVENOT, 1991). Dessa maneira, em um mundo encontra-se a justificação de determinados valores. Cada um deles estabelece as bases de uma ordem. A seguir, cada um dos seis modos de coordenação será caracterizado:

a) O mundo inspirado: tem como princípios a humanidade comum e a não exclusão. A convenção é de inspiração à emergência de ideias originais e inovadoras, em que as informações são emocionais;

b) $\mathbf{O}$ mundo doméstico: transmite a ideia da relação pessoal e próxima entre os agentes, em que a ordem é a confiança. Baseia-se na tradição e confiança quanto a pessoas ou marcas como resultado do conhecimento pessoal e regularidade das transações;

c) $O$ mundo da opinião: o princípio é de diferença, em que se leva em conta a opinião de outros e a reputação de empresas, produtos ou marcas;

d) O mundo cívico: com o princípio de bem-estar comum, prevalecendo o interesse coletivo, onde a relação elementar é a solidariedade;

e) $\mathbf{O}$ mundo industrial: contém o princípio da existência de ordens de grandeza, em que prevalece a noção de produtividade, e os valores são produtos da eficiência e padronização;

f) O mundo do mercado: sob o princípio da noção de investimento, em que a diferença é justificada pelo sacrifício ou esforço envolvido. O modo de funcionamento é o mercado, avaliado pelo preço e organizado pela competitividade por meio das relações de troca.

As decisões por parte dos agentes refletem uma abordagem comparativa entre vários mundos possíveis, várias formas de relacionamento e vários planos de ação (EYMARD-DUVERNAY e FAVEREAU, 1996). Cada uma dessas formas de coordenação contém princípios que servem para qualificar os produtos, assim, são convenções de coordenação entre os atores. Nenhuma ordem de justificação, de acordo com Thévenot (1996), é suficiente para governar sozinha a complexidade 
da coordenação em uma sociedade organizada e de confronto entre as diferentes formas de justificação que requerem acordos. Em consequência, no conjunto, os mundos compõem uma complexa rede de atores.

Muitas vezes, a construção social da qualidade dos produtos envolve múltiplos atores e interesses que raramente convergem (BARREY e VALCESCHINI, 2006). Renard (2003) observa que a construção consiste em duas vias: a introdução de instituições coletivas que estabeleçam normas de qualidade e meios para sustentá-las ou o reconhecimento de vínculos entre os atores locais que lhes permitam comunicar-se e negociar.

\section{Metodologia}

Para cumprir o objetivo do estudo, desempenhou-se uma pesquisa em nível exploratório. As pesquisas exploratórias, de acordo com Gil (2007), conferem maior familiaridade com o problema, de maneira a torná-lo mais explícito ou a construir hipóteses. Assim, neste estudo, em um primeiro momento, conhece-se melhor o tema e, em seguida, trata de identificar fatores.

$\mathrm{O}$ enfoque dado à pesquisa é qualitativo. Conforme Denzin e Lincoln (2006, p. 23), os pesquisadores qualitativos caracterizam-se por ressaltar "a natureza socialmente construída da realidade, a íntima relação entre o pesquisador e o que é estudado, e as limitações situacionais que influenciam a investigação". Ainda, as pesquisas qualitativas centram-se na natureza repleta de valores da investigação e buscam soluções para as questões de como a experiência social é criada e adquire significado (DENZIN e LINCOLN, 2006).

O objeto e o espaço da pesquisa, por sua vez, ficam delimitados à microrregião do Vale dos Vinhedos e ao segmento de vinhos finos. Em especial, o Vale dos Vinhedos corresponde a um espaço geográfico delimitado, composto por parte dos municípios de Bento Gonçalves, Garibaldi e Monte Belo do Sul, que se apresenta com destaque na produção nacional de vinhos finos. A área demarcada, abrangendo parte dos três municípios gaúchos, corresponde aos estudos para reconhecimento de indicações geográficas no local.

A amostra para a realização do estudo foi selecionada de forma não probabilística. Observam-se, tendo em vista as atividades desenvolvidas e o relacionamento entre os agentes, as organizações e as instituições. No caso das organizações, considera-se a integração entre a atividade vitivinícola e demais atividades correlacionadas que, no conjunto, produzem o enoturismo. Portanto, foram selecionados empreendimentos na categoria de produtores vitivinícolas; de gastronomia (restaurantes, cafés coloniais, queijaria); de hospedagem (pousadas e hotéis); e na de outros estabelecimentos que caracterizam uma oferta de comércio e serviços de entretenimento (casas de artesanato, espaços de atração cultural, memoriais e agências de turismo). Assim, selecionaram-se empreendimentos situados no Vale dos Vinhedos e que participam da Associação dos Produtores de Vinhos Finos do Vale dos Vinhedos (Aprovale). Atenderam à pesquisa três vinícolas, três empreendimentos gastronômicos, três empresas do serviço de hospedagem e quatro na categoria de comércio e serviços de entretenimento.

As instituições selecionadas referem-se a associações de classe, órgãos ligados à pesquisa e ao desenvolvimento, instituições de ensino e entidades relacionadas ao planejamento do turismo. Participaram do estudo: Associação Brasileira de Enologia (ABE); Associação dos Produtores de Vinhos Finos do Vale dos Vinhedos (Aprovale); Conselho Municipal de Turismo de Bento Gonçalves (Comtur); Empresa Brasileira de Pesquisa Agropecuária Uva e Vinho (Embrapa Uva e Vinho); Instituto Brasileiro do Vinho (Ibravin); Instituto Federal de Educação, Ciência e Tecnologia do Rio Grande do Sul - Campus de Bento Gonçalves (IFRS-BG); Sindicato de Hotéis, Restaurantes, Bares e Similares da Região Uva e Vinho (SHRBS); Universidade de Caxias do Sul - Campus Universitário da Região dos Vinhedos (UCS-Carvi); União Brasileira de Vitivinicultura (Uvibra). 
O instrumento utilizado para a coleta dos dados primários consiste de entrevistas. $\mathrm{O}$ tipo de entrevista caracteriza-se como semiestruturada. De acordo com Triviños (1990, p. 116), a entrevista semiestruturada é:

Aquela que parte de certos questionamentos básicos apoiados em teorias e hipóteses, que interessam à pesquisa, e que, em seguida, oferece amplo campo de interrogativas, fruto de novas hipóteses, que vão surgindo à medida que se recebem as respostas do informante. Desta maneira o informante, seguindo espontaneamente a linha do seu pensamento e de suas experiências dentro do foco principal colocado pelo investigador, começa a participar na elaboração do conteúdo da pesquisa.

Além disso, reuniram-se dados de caráter secundário para complementar a discussão e, ainda, realizar a caracterização e descrições acerca do tema. No que diz respeito ao período de abrangência da pesquisa, o intuito foi retratar a produção do cenário atual da microrregião, portanto, considerando os aspectos do comportamento passado e presente dos agentes estudados, de forma a observar as implicações. As entrevistas com as organizações e as instituições foram realizadas entre agosto e outubro de 2010.

Considera-se, assim, a coordenação dos agentes envolvidos com o território, as organizações e as instituições, observando-os sob a perspectiva de suas capacidades e de seus valores. Na Figura 1, tem-se a proposta de modelo teórico-analítico, com base nos preceitos da teoria das convenções, a fim de que essa orientação seja seguida na discussão dos resultados.

Acima estão os "mundos" de coordenação e os princípios orientadores destes são os triângulos abaixo, ambos com base na teoria das convenções. Os quadros pontilhados representam os fatores econômicos, sociais, históricos e culturais, identificados para o caso do Vale dos Vinhedos.

Figura 1. Modelo Teórico-Analítico

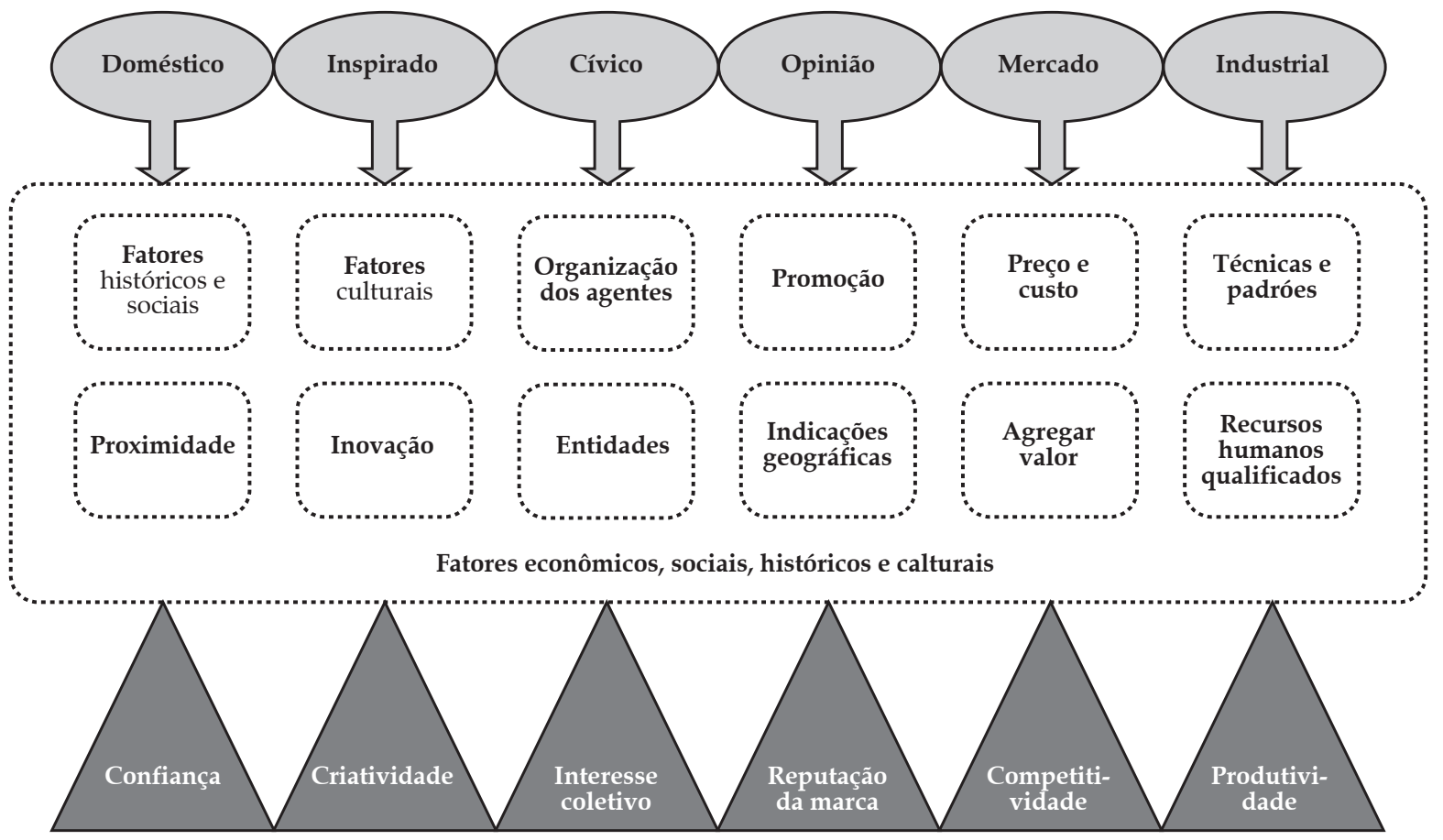

Fonte: Elaboração do autor. 


\section{Resultados e discussão}

Nesta seção, são desenvolvidas a apresentação e a análise dos dados. A partir das informações coletadas, dos resultados obtidos, discutem-se os valores, as ações e os relacionamentos pertinentes em um ambiente socialmente construído, que envolve várias dimensões, sejam elas de ordem econômica, social, cultural, ambiental, e que guiam para a conjugação dos elementos que reportam à qualidade do produto vinho fino na microrregião considerada.

\subsection{Os atores no ambiente vale dos Vinhedos}

A atividade da vitivinicultura na região da Serra Gaúcha do Rio Grande do Sul e, mais especificamente na microrregião do Vale dos Vinhedos, merece atenção especial em virtude de suas peculiaridades. Em primeiro lugar, a produção vitivinícola está diretamente e de maneira veemente ligada à história regional, ou seja, a história da imigração e da colonização italiana na região. Consequentemente, o conhecimento, os hábitos e os valores do povo italiano inscreveram a formação social e cultural do espaço em que se assentaram.

Posteriormente aos fatores históricos, sociais e culturais que fundamentam a microrregião, encontra-se no entorno um chamado Arranjo Produtivo Local (APL) Vitivinícola. Trata-se de um conjunto de produtores e empresas ligadas direta ou indiretamente ao setor vitivinícola, além de associações de produtores, instituições públicas e privadas e a atuação de órgãos públicos, todos aproximados em um espaço geográfico e interessados na causa de um setor particular; nesse caso, o vitivinícola.

Nesse processo de desenvolvimento, em outro momento, a atividade direciona-se para a ocasião das indicações geográficas no Brasil. De modo geral, as indicações geográficas ligam um saber-fazer a um território. A Indicação de Procedência Vale dos Vinhedos (IPVV) foi a primeira indicação geográfica reconhecida do Brasil, e a
Denominação de Origem Vale dos Vinhedos vem a ser a primeira brasileira para vinhos em 2012.

Assim, todo o contexto descrito pressupõe organização e coordenação de objetivos comuns. Os agentes da organização e da coordenação são os indivíduos, atuando em suas atividades, compondo as classes de produtores, empresas, associações, instituições públicas e privadas.

\subsubsection{Organizações}

As vinícolas, tal como centro motivador, figuram como a atividade que persuade as demais; assim, são o tipo de empreendimento que está há mais tempo inserido na região. Porém, é preciso destacar que os empreendimentos vinícolas que existem atualmente no Vale dos Vinhedos antes eram apenas pequenos produtores de uvas comuns e alguns até de uvas Vitis viniferas (uvas para a produção de vinhos finos). Posteriormente, produtores passaram a se constituir em empresas vinícolas familiares, voltando-se, assim, para a comercialização dos vinhos comuns inicialmente; e, após, se desperta a produção dos vinhos finos. A estrutura dessas indústrias tornou-se bastante moderna no decorrer dos anos, visto que foram adaptando o processo produtivo para obter maior qualidade. Ocorreram inovações quanto ao método de condução das videiras, à inserção de tanques de aço inoxidável na produção dos vinhos e espumantes e à prática de amadurecimento dos vinhos com utilização de barricas de madeira de carvalho francês. Em geral, as vinícolas analisadas iniciaram as atividades de maneira formal entre as décadas de 70 e 90; além disso, a maior parte dos proprietários é descendente dos primeiros imigrantes italianos que chegaram à microrregião. Desse modo, a homenagem e a conservação da cultura italiana ficam evidentes, principalmente no que se refere às vinícolas.

No segmento gastronômico, tem-se a atuação de empresas que começaram no Vale dos Vinhedos logo com a aquisição da IPVV, principalmente. Inclusive alguns restaurantes são de propriedade das próprias vinícolas que vislumbraram essa oportunidade de negócio 
e a permanência do cliente por mais tempo em seu estabelecimento. Assim como restaurantes, queijarias e casas de café colonial, as pousadas e os hotéis foram construídos nesse mesmo período, além dos espaços de cultura, de artesanato e as agências de turismo que iniciam também, nessa época, suas atividades.

Os empreendimentos analisados buscam aliar seus produtos e serviços à história e à cultura, seja na oferta de produtos coloniais, de pratos típicos da gastronomia regional, ou mesmo na arquitetura das pousadas e hotéis, nas atrações culturais e no artesanato local. A oferta de produtos e de serviços complementa-se, a fim de satisfazer o turista que veio motivado pela sua curiosidade em conhecer o ambiente da produção vitivinícola, e também com o intuito de criar um fluxo de visitantes que seja favorável à comercialização dos seus produtos. Portanto, figuram empreendimentos aglomerados em um ambiente, formando a atividade do enoturismo e orientados pela Aprovale no que diz respeito à condução da área demarcada Vale dos Vinhedos. Com base na definição de Valduga (2007), o enoturismo coloca em circuito os segmentos gastronômico e hoteleiro, mais o entretenimento que fica por conta da paisagem dos vinhedos, da história e da cultura vitivinícola interpretada em museus, memoriais e atrações típicas e, fundamentalmente, o viticultor e o vinicultor que oferecem o sabor da uva e do vinho.

\subsubsection{Instituições}

Dentre as instituições de importância para o desenvolvimento do Vale dos Vinhedos e que cingem causas de interesse às atividades ali inseridas, tem-se, na área de pesquisa aplicada, a instalação de uma unidade da Embrapa na região com foco na uva e no vinho, sendo relevante para o avanço do setor no âmbito da produção. Foi fundada em 1975; porém, a história de um centro de pesquisa nesse campo já perfaz 70 anos. Sua missão é bastante abrangente, visto que procura gerar tecnologias, informações e conhecimento, com o objetivo de garantir o desenvolvimento sustentável da vitivinicultura em alcance nacional, de forma que atua em diferentes frentes, problemas e complexidades, atendendo pequenos, médios e grandes produtores, estejam estes produzindo uvas de mesa, Vitis viniferas, vinhos comuns, ou vinhos finos.

Em referência à formação de pessoal qualificado para atuar nos setores e regiões, os precedentes remontam às instituições de ensino. O IFRS-BG e a UCS-Carvi são duas instituições de significância na região. A primeira, com a disponibilidade dos cursos específicos de Viticultura e de Enologia, destacadamente; e a segunda, com oferta de cursos de formação em diversas áreas do conhecimento.

No que se refere às classes, a entidade composta que une organizações e associações da vitivinicultura no Brasil é a Uvibra. Por meio de projetos, participa na promoção dos vinhos e dos espumantes de Vitis viniferas, sucos de uva e destilados do vinho. Foi fundada em 1967 e contém associados dos estados do Rio Grande do Sul, Santa Catarina, São Paulo, Bahia e Pernambuco. O escopo principal é defender os interesses das empresas da vitivinicultura, por meio de defesa mercadológica, de relacionamento com os governos para tratar da legislação e questões tributárias, além de fazer um trabalho de união do setor que versa sobre as negociações e links entre produtores e empresas, considerando-se que estão mais voltados para a produção dos vinhos finos, espumantes e sucos.

Outra associação identificada é a ABE, para a categoria dos enólogos. Em 2012, tinha cerca de 310 associados, com aproximadamente $80 \%$ localizados na Serra Gaúcha, mas também conta com associados nos estados do Paraná, Santa Catarina, São Paulo, Minas Gerais e região Nordeste. Destaca-se como principal objetivo da associação o fortalecimento e o aprimoramento dos trabalhos dos enólogos na viticultura e até mesmo na área de mercado do vinho, embora esteja principalmente concentrado na etapa de vinificação, ou seja, a transformação da uva em 
vinho. Desse modo, aprecia-se a importância desses profissionais atuando nas vinícolas e ajustando a qualidade da elaboração dos vinhos.

Enquanto a Aprovale constitui-se em uma associação dos produtores de vinhos finos da microrregião e também possui, como associados a ela, outros tipos de empreendimentos que não são vinícolas, mas que complementam a oferta turística do Vale dos Vinhedos, os chamados associados setoriais. Em seu estatuto, a Aprovale é definida como uma instituição cultural, social, de pesquisa, sem fins econômicos. Assim é o organismo central no Vale dos Vinhedos, que define objetivos e tem procurado influenciar as ações para a microrregião.

Esta associação foi formada em 1995, coincidindo com o planejamento para o registro de uma indicação geográfica para o Vale dos Vinhedos, pois quando se pensou no potencial existente para explorar uma certificação desse tipo, necessitou-se de uma entidade intermediadora para articular os objetivos e as ações demandadas. O diretor do conselho regulador assinala que foi um trabalho técnico de 15 anos, envolvendo uma série de trâmites e trabalhos desde os vinhedos, a forma de condução dos vinhedos, até o produto final. De maneira que se acompanhou o comportamento dos vinhedos e dos vinhos, definindo, através de trabalhos técnicos de elaboração e degustação, as melhores variedades de uvas para os vinhos brancos, tintos e espumantes. Sobretudo, houve a criação de uma microrregião, tal como uma associação para gerir os interesses de produtores com foco em vinhos finos e ali situados.

Segue, por sua vez, outra instituição que tem se empenhado na divulgação do vinho brasileiro e na destinação dos recursos para o setor vinícola junto a órgãos públicos. O Ibravin foi criado em 1998 e apresenta como membros as entidades do segmento dentro do território nacional. Tem por missão ordenar e promover o desenvolvimento setorial, ou seja, ordenar as políticas que organizem e deem competitividade ao setor e promover programas de promoção do produto oriundo da vitivinicultura brasileira. Além disso, a atuação do Instituto é, de certa forma, limitada em função da concentração da vitivinicultura no Rio Grande do Sul e dos investimentos através do Fundo de Desenvolvimento da Vitivinicultura (Fundovitis). Todavia, a realização dos trabalhos tende a ser de abrangência nacional de fato; mas, para isso, cada estado terá de se estruturar e encontrar mecanismos de captação de recursos; em outras palavras, um processo de organização setorial.

Em consequência, dada a divulgação do produto vinho, bem como da área que o produz e que instiga a curiosidade e o prazer das pessoas em conhecê-los, abastecida pelos valores sociais e culturais que caracterizam a produção na vitivinicultura, mostra-se o turismo ou, propriamente, o enoturismo na microrregião. Em vista disso, identificou-se a atuação do SHRBS e do Comtur em projetos para o turismo. O foco do sindicato tem três diretrizes básicas, além da assessoria básica ao associado: capacitação e qualificação, inovação e promoção. O Comtur é um conselho ligado à Secretaria Municipal de Turismo de Bento Gonçalves, em que, na sua constituição, há representantes de diversas classes preocupadas com o turismo na região. $\mathrm{O}$ principal papel do conselho é auxiliar o poder público atuando junto às forças econômicas que trabalham e impulsionam o desenvolvimento do turismo, aliados à proposta do Ministério do Turismo sobre a questão de destino indutor. Dessa forma, esses compõem a estrutura para fazer a gestão e o planejamento do destino indutor.

Assim, as diversas entidades atuam, seja representando uma classe econômica, seja com foco social no ensino, seja na pesquisa ou desenvolvimento do setor vitivinícola e turístico, ao lado dos empreendimentos de produtores vitivinícolas, de gastronomia, de hospedagem e de entretenimento, os quais dispõem seus produtos e serviços à satisfação da sociedade. A respeito disso, verifica-se uma rede de atores que constrói uma ligação entre suas capacidades, que se complementam e que serve, sobremaneira, à qualidade do produto, os vinhos finos, além de instigar o desenvolvimento local, visto que há base para tecnologia, conhecimento, recursos 
humanos qualificados e para a governança. Assim, aparece a produção de vinhos finos, pertencente a um segmento de mercado acirrado, em que o atributo de qualidade pode conferir diferencial e ganhos na competitividade.

\subsection{Coordenação: \\ convenções e seus princípios}

A mediação entre economia e sociologia, dada pela teoria das convenções, será aplicada para entender o caso da construção social no Vale dos Vinhedos, identificando as relações que perpassam questões pertinentes aos seis modos de coordenação. A análise seguirá o modelo teórico-analítico proposto (Figura 1).

\subsubsection{Convenção de mercado}

Encontram-se nesta coordenação as relações de preço e de mercado. Aqui, o princípio de medida é a competitividade. A respeito disso, o relacionamento entre os agentes envolvidos no processo do Vale dos Vinhedos compreende vários aspectos.

Inicialmente, o segmento de vinhos finos insere-se em um ambiente de mercado acirrado para os produtos nacionais. Os vinhos do Velho Mundo possuem grande aceitação no mundo todo e, ao lado desses, também concorrem os vinhos do Novo Mundo, representados por países como Argentina, Chile, Austrália e África do Sul, principalmente. O Brasil empreende pertencer a este grupo, porém, se depara com o desafio de não ter o seu vinho conhecido no mercado mundial e de não ser valorizado no mercado nacional. Muitos são os movimentos do setor para que o vinho brasileiro encontre seu espaço e que, progressivamente, efeitos positivos começam a ser sentidos.

Garantir competitividade ao setor vitivinícola brasileiro tem sido a maior motivação dos seus agentes. Nota-se que as ações voltam-se, sobremaneira, para esse propósito. A união do setor move-se em torno disso, visto que o recurso oportuno é de que a inserção no mercado seja mais facilmente alcançada se exercida por meio da atuação do seu conjunto do que individualmente.

Por sua vez, trata-se sobre a questão dos preços no mercado dos vinhos finos. A priori, o preço é um modo de avaliação do produto. Contudo, a formação de um preço é condicionada por diversos fatores e eles nem sempre são reflexo de genuína qualidade do produto ou serviço. Nesse caso, tem-se o custo de produção como componente essencial. Os vinhos finos no Brasil são os que perpassam por mais desafios, pois necessitam de mais investimentos em tecnologia e trato no cultivo e na elaboração, por isso, o seu custo de produzir também é mais elevado. Os tributos que incidem sobre o produto são repassados ao consumidor final, e tem sido uma reclamação frequente dos produtores o fato da tributação da bebida ser muito elevada.

Além disso, o consumo de vinhos finos no Brasil é muito baixo e está concentrado na parte da população que possui renda mais elevada e grau mais elevado de escolaridade. Para atender esse público, que geralmente tem conhecimento sobre o vinho, é preciso cuidar da qualidade e também da apresentação do produto. Então, conforme já mencionado, a competição é elevada nesse segmento, dado que os vinhos nacionais têm dificuldade de concorrer com os produtos estrangeiros que se assemelham em qualidade e que têm preço mais baixo, em virtude de vantagens procedentes de outras condições de produção nesses países, que permitem chegar ao mercado brasileiro a valores mais competitivos.

Entretanto, os preços podem ser justificados pela diferenciação do produto. De modo geral, o diferencial provém de mecanismos para agregar valor. Assim, as indicações geográficas, IP e DO, são formas de se diferenciar um produto, em que a justificativa de agregação de valor é o território e métodos típicos de produção no local. Dessa maneira, o uso de um selo geográfico refletese no preço da valorização dessas características peculiares e que são irreprodutíveis em outro ambiente. A conquista da Indicação de Procedência Vale dos Vinhedos acrescentou o preço dos vinhos com qualidade atestada pelas 
exigências da indicação em um percentual de $20 \%$ a $30 \%$, em média. Do mesmo modo que se valoriza o produto produzido no local específico, apreça-se também o próprio território; logo, as terras no Vale dos Vinhedos tiveram aumento substancial. Se, antes do fato, as terras custavam em torno de R\$ 5 mil por hectare, hoje são vendidas de $\mathrm{R} \$ 100 \mathrm{mil}$ até $\mathrm{R} \$ 500 \mathrm{mil} /$ hectare.

Além disso, observa-se que a tendência dos vinicultores na microrregião é de se enquadrar em uma estrutura de oligopólios. O produto é sensivelmente diferenciado, ao lado de um número moderado de ofertantes e protegidos pela barreira de altos investimentos que a atividade vinícola exige, ainda mais se considerado o diferencial do selo geográfico.

A produção de vinhos finos vem assumindo integração totalmente verticalizada, em que o vinicultor possui parreirais próprios, com a finalidade de controlar o processo de qualidade de suas uvas. Além disso, com o advento da IPVV, que promoveu substancialmente o enoturismo, a comercialização dos vinhos no próprio estabelecimento para os turistas foi de significativa vantagem para as vinícolas, tendo em vista o corte com os gastos de distribuição e o aumento das vendas, dado o volume maior de turistas na região.

Enfim, são muitas as variáveis em um mercado, as quais, inclusive, relacionam-se com questões pertinentes nos demais mundos de coordenação. Pode-se dizer que as qualificações contidas nas demais convenções podem se converter em argumentos para propósitos econômicos.

\subsubsection{Convenção industrial}

Com relação ao modo de agir na ordem industrial, o princípio preponderante é a produtividade. Os vinhos finos apresentam um posicionamento bem particular a respeito de produtividade. Neste caso, releva-se a questão de investimentos, tecnologia, padrões e normas técnicas etc., os quais interferem na eficiência produtiva.

A relação da qualidade do vinho fino com a produtividade é quase que determinante. A matéria-prima, a uva, é elemento primordial de qualidade em qualquer espécie de vinho produzido. A uva de Vitis vinifera preceitua cuidados maiores em sua produção. $\mathrm{O}$ seu cultivo em pequena extensão de área viabiliza isso, além de contribuir com a preservação das características da variedade, em que produtividade elevada não é desejável. Na avaliação para delimitar as variedades Vitis viniferas que mais se adaptavam ao território do Vale dos Vinhedos com potencial para fazer parte de um processo de IG, diversos fatores foram levados em conta, estabelecendo, assim, normas e padrões a serem seguidos, dentre eles, o nível de produtividade.

Após a etapa de considerar a qualidade da matéria-prima, o processo de vinificação também deve ser cauteloso, de forma que, nesta fase, a tecnologia exerce influência sobre o resultado de um bom vinho. Outro ponto imprescindível de interferência na qualidade, bem como nos níveis de produtividade, é o trabalho dos enólogos, de modo que o reflexo do conhecimento destes é sensível na elaboração do vinho. Dessa forma, estes fatores de qualidade, tais como o nível ideal de produtividade e demais padrões e normas estabelecidos principalmente pelos requisitos de IG, aparecem como reflexo do investimento tecnológico e da habilidade dos profissionais nas etapas produtivas.

Ampliando a questão de recursos humanos qualificados, o diretor do IFRS-BG salienta que, inicialmente, o perfil de formação era preparar os alunos para o seu mercado técnico de trabalho, para atuar nas grandes cooperativas e empresas da época. Mas, desde o crescimento de indústrias familiares, este cenário alterou-se, pois o profissional tem de ser preparado para, além de desempenhar sua função técnica, ter noções de como gerir o negócio e tomar decisões. Assim, o trabalho é voltado para todas as etapas do negócio, desde a elaboração da uva e do vinho até a comercialização.

Por fim, outro fator de eficiência na vitivinicultura é a constituição do arranjo produtivo. $\mathrm{O}$ fato de ter essa diversidade de entidades e produtores organizados é preeminente para 
que as atividades tenham a disponibilidade de recursos de várias ordens, fazendo com que a tendência seja o funcionamento de maneira otimizada. Obviamente, existem problemas e desafios na articulação do arranjo, mas a proximidade entre os agentes, suas capacidades e o fluxo de informações apresentam-se como gerador de uma eficiência produtiva que se manifesta de modo coletivo. Quanto maior a cooperação dos agentes em torno de objetivos comuns e democráticos, espera-se que esses benefícios sejam também maiores. Isso tudo será refletido no savoir faire, ou saber-fazer, das atividades e do território.

\subsubsection{Convenção de opinião}

Pode-se analisar que a convenção da opinião está bastante presente no ambiente da vitivinicultura, mais especificamente no caso dos vinhos finos, bem como na microrregião do Vale dos Vinhedos. A coordenação no mundo da opinião segue o princípio do renome, a reputação das marcas.

De acordo com Thévenot (1996), do ponto de vista da teoria convencionalista, as marcas são sinais que garantem ao cliente um teste de qualidade através da verificação do que ele comprou e do que ele espera obter. $\mathrm{O}$ desenvolvimento de marcas de qualidade pode ser visto como uma expressão da vontade de aplicar e tornar mais visível os vários tipos de coordenação entre os agentes. As características e o uso de marcas, portanto, podem ajudar a compreender os tipos de convenções de qualidade inerente ao produto, o tipo de armas convencionais para o segmento de consumo, bem como os mecanismos de coordenação entre os operadores em vários níveis do processo de produção ao longo do espaço e tempo.

Nesse aspecto, encontram-se várias ações para dar visibilidade aos vinhos brasileiros. Por um lado, têm-se as campanhas publicitárias como fruto do marketing intenso que vem sendo desenvolvido, especialmente coordenadas pelo Ibravin. As campanhas desenvolvidas têm caráter coletivo, identificação coletiva, em que os produtores e produtos podem se valer dos seus benefícios. Todavia, a divulgação faz parte de pretensões maiores, com foco no mercado interno e internacional. São projetos que compõem um aparato logístico e financeiro para que campanhas publicitárias e outros meios de divulgação, como a participação em feiras e concursos, sejam desempenhados.

A respeito da campanha "Vinhos do Brasil", pode-se dizer que significa uma mudança bastante complexa, uma vez que tem o propósito de aceitação do produto nacional e de aumento do seu consumo. Isto envolve, sobretudo, uma mudança de aspecto cultural no hábito de consumir vinhos no País. O consumo per capita de vinhos no Brasil é baixo, e o crescimento desse consumo deve levar mais tempo para acontecer, em vista de alguns fatores culturais.

O projeto "Wines of Brasil", de modo semelhante, visa reconhecimento e ganhos de mercados no âmbito internacional. Esses escopos viabilizam-se através da participação em feiras e eventos internacionais, de projetos de imagem ao cliente, promovendo a marca Brasil, e da assessoria para as vinícolas em comércio exterior. Desse modo, divulga-se o vinho brasileiro ao mundo com vistas à sua valorização, e clientes mundiais são atraídos.

Assim, de outro lado, identifica-se o caso de indicações geográficas. As certificações são o fruto de uma forma mais geral, um esforço constitucional de referências comuns, de transmissão de informação em uma economia cognitiva. Como resultado, o formato usado pela informação contida na marca deve ser coerente e vinculado aos mecanismos de coordenação, conforme as ideias de Thévenot (1996).

Tanto a Indicação de Procedência quanto a Denominação de Origem são dois mecanismos robustos de projeção e proteção de uma imagem. No primeiro caso, propaga-se a imagem da região conhecida pela produção de determinado produto; então, valorizam-se a região e o seu produto. No segundo, designa a imagem de um produto afirmada por sua qualidade associada 
ao seu meio; logo, o destaque é para o produto específico de uma região.

Em relação ao Vale dos Vinhedos, é exatamente essa tendência de divulgação que o produto e a região vêm assumindo. Com a obtenção do selo de IP, a microrregião alcançou tamanha visibilidade em todo o País e até mesmo internacionalmente, como área produtora de vinhos finos e por ser a primeira no Brasil a mobilizar-se para explorar o potencial de uma IG. Com a atenção voltada para o Vale dos Vinhedos, os primeiros resultados foram o aumento do turismo e da identidade do produto.

Aí renasce o enoturismo na região, exigindo que as expectativas dos turistas sejam supridas pelas vinícolas, como também de empreendimentos relacionados, que são essenciais para acolhê-los, tais como serviços de hospedagem, gastronomia, artesanato e atrações culturais. Desse modo, geraram-se oportunidades para assentar outros ramos de negócios. Quanto ao vinho, ele foi o produto motivador de todo o processo que ocorreu, já remetendo à IP como uma identificação da sua qualidade.

Porém, a perspectiva é de que essa associação com a qualidade de forma mais intensa seja auferida a partir da Denominação de Origem, concedida em setembro de 2012, pois o rigor no controle do produto deve ser maior e, assim, espera-se que a melhoria da qualidade dos vinhos seja transmitida e reconhecida pelos consumidores. Por isso, o esforço de uma qualidade com identidade tem de ser constante e inconteste, contando com unidade e confiança entre agentes.

Outra particularidade que pode ser proporcionada por uma indicação geográfica situa-se no seu caráter permanente. A tendência é de que regiões que empreendem uma indicação geográfica, identificando a qualidade diferenciada do produto ali produzido e desfrutando da potencialidade enoturística, obtenham uma fama que se conserva ao longo dos anos. De fato, parece ser um ciclo virtuoso impulsionado pela visibilidade e comunicação. Pois, à medida que se divulga, por meio de campanhas publicitárias, marcas, certificações, participação em feiras e em concursos, e o produto condiz, o consumidor responde com sua demanda. Assim, tanto maior a valorização do consumidor, maior a divulgação espontânea que é gerada.

Enfim, esses meios de promoção relatados têm um fator de desenvolvimento em que os ganhos são coletivos. Entretanto, as empresas vinícolas possuem suas marcas individuais que, em sua maioria, levam o nome da família. Para algumas, o seu maior patrimônio é a própria marca, enquanto que, para outras, se valer do apelo geográfico é um diferencial essencial para o seu negócio. Esse aspecto coletivo é de importância, sobretudo, para as empresas que não têm sua marca conhecida no mercado; assim, adquirem espaço para seus produtos com o marketing administrado de forma coletiva.

Dessa forma, em um sentido geral, ressaltase o papel da promoção para atingir o consumo. Muitas vezes, ela pode ser formadora de opinião. Para Thévenot (1996), reforçar a imagem da marca representa convenção ativa de qualidade, sinalizando a sua presença pelos atores. Cada tipo de marca pode ser entendido como apoio para uma convenção de qualidade especial.

\subsubsection{Convenção cívica}

A ordem no mundo cívico da teoria das convenções é a coletividade. Aqui, os atores agem em torno da coordenação de objetivos comuns. Portanto, buscam maximizar o bem comum para todos.

O Vale dos Vinhedos, assim como a vitivinicultura no Rio Grande do Sul, é exemplo de desenvolvimento em que um dos diferenciais é a organização coletiva, visto que as conquistas do setor, obtidas até o momento, vieram de ações coletivas estimuladas por interesses que convergiam. Assim, as reivindicações dos agentes são deferidas à proporção de sua representatividade.

A criação da Aprovale, em 1995, enquadra-se nesta questão. A partir do cenário de mercado que não se mostrava satisfatório ao setor, produtores percebiam que era necessário reagir, e 
assim encontraram a conveniência de adquirir uma indicação geográfica. Para isso, em função dos estudos necessários para a região e os vinhos, dos trâmites de registro, da busca de apoio para realizar esses requisitos, criou-se a associação com a finalidade de viabilizar o processo, reunir as demandas e governar seus interesses. Para Flexor (2005), o modo de desenvolvimento dos mercados de produtos específicos dependerá das redes de atores envolvidos e das normas implementadas.

Então, foi acerca disso que produtores se organizaram, visualizando o ganho coletivo mercadológico do seu produto e da atividade enoturística. Particularmente, o enoturismo tem a capacidade de levar adiante essa proposta de ganhos coletivos, já que o seu funcionamento pressupõe o desenvolvimento de um conjunto de atividades para entreter o turista. Logo que o destaque esteve concentrado na região, surgiu a oportunidade de destacar e incentivar o que dela faz parte.

Conforme mencionado o apoio de que necessitou a Aprovale para executar seu projeto, salienta-se o trabalho de instituições que fazem parte do Arranjo Produtivo Local Vitivinícola. Aliás, a mobilização dos agentes, em busca de desenvolver ações para contornar os principais problemas e desafios do setor, é preponderante para obter resultados positivos para o conjunto. Por exemplo, entre outros desafios tratados, o problema da tributação sobre os vinhos é questão bastante debatida. Um mecanismo proposto e recentemente aprovado é a utilização de um selo fiscal para os vinhos no Brasil. A partir desse selo, espera-se impedir a sonegação fiscal, dificultar a comercialização dos vinhos importados em descaminho, além de coibir a entrada de vinhos falsificados no mercado.

Todavia, além dos ganhos socioeconômicos, o caso da indicação geográfica carrega consigo um acordo de qualidade do produto entre as partes. O acordo da qualidade é estabelecido formalmente através do regulamento de uso, no qual ficam estabelecidos a área de produção, as cultivares, o sistema de produção das variedades, bem como os limites e padrões para a elaboração do produto. Desse modo, o regulamento contém as normas e padrões que devem ser seguidos pelos produtores que usufruírem do selo de indicação geográfica.

Assim, a qualidade é orientada coletivamente; em vista disso, o sucesso do produto dependerá do comprometimento de cada um e da seriedade no processo da atividade. Renard (2003) observa que a construção consiste em duas vias: a introdução de instituições coletivas que estabeleçam normas de qualidade e meios para sustentá-las ou o reconhecimento de vínculos entre os atores locais que lhes permitam comunicar-se e negociar.

\subsubsection{Convenção doméstica}

Na convenção doméstica, encontra-se uma relação de proximidade entre os agentes. Uma relação pessoal e próxima pode ocorrer em virtude de fatores históricos e sociais que suscitam o hábito e a tradição. Dado isso, a confiança tornase um princípio básico de relacionamento.

Primeiramente, verifica-se uma dualidade entre o ser empreendedor e associativista. É paradoxal no sentido de que os agentes, notadamente as organizações, carregam consigo uma capacidade ativa para os negócios, em que a competitividade é um princípio estimulante. De outro modo, têm uma tendência reivindicatória que motiva a organização coletiva, em que buscam apoio para encorajar seus ideais de desenolvimento. A confiança, portanto, é reforçada por um lado e enfraquecida por outro. Todavia, a conexão são os laços históricos e hábitos.

No ambiente Vale dos Vinhedos, a formação histórica e social constitui-se em um fator pujante. A vinda dos imigrantes italianos com a instalação na região foi relevante, especialmente para o desenvolvimento da atividade vitivinícola. Estes contribuíram com a sabedoria do cultivo das videiras e da elaboração do vinho.

A relação doméstica e habitual também pode ser um modo de avaliação na troca dos produtos e serviços. A tradição em uma atividade gera um sentimento de confiança por parte dos 
consumidores de um produto em relação aos seus produtores. Assim, a confiança manifesta-se como um elemento presente nas transações de troca. De certa forma, os vinhos produzidos no Vale dos Vinhedos são também transacionados dessa forma; por isso, a vinculação feita com a tradição do local na vitivinicultura é sempre mencionada e frisada. Nesse caso, remete-se ao denominado atributo de crédito, conforme definido por Ponte e Gibbon (2005).

No processo de registro para a IG, teve de ser feito um levantamento histórico e social da microrregião para que se justificasse o tradicionalismo do território e dos indivíduos com a atividade vitivinícola. Então, o território do Vale dos Vinhedos é um dos seus patrimônios, ao lado da história e cultura. A preservação destes é fundamental a caminho de um desenvolvimento sustentável. Nesse sentido, há uma questão controversa no Vale dos Vinhedos, que é o caso de construções de conjuntos habitacionais na microrregião. O Vale dos Vinhedos é um espaço essencialmente rural, onde estão as áreas de vinhedos, as vinícolas, os empreendimentos criados como hotéis, pousadas, restaurantes, casas de artesanato e outros, junto aos moradores, famílias de produtores e trabalhadores nas atividades de uvas e de vinhos.

De um lado, posicionam-se as pessoas que argumentam que as habitações de terceiros descaracterizariam a microrregião, contrariando o aspecto que foi construído de um ambiente marcado pela paisagem vitivinícola e tranquilidade típica de um meio rural. De outro, as residências acomodariam a demanda por moradia devido ao crescimento da população nas cidades, além de evitar a proliferação de domicílios irregulares que se instalam no entorno dos municípios.

Quanto aos habitantes no território, outro ponto é pertinente. A respeito disso, discute-se sobre o êxodo rural. Anteriormente, quando o negócio vitivinícola passava por uma crise, o êxodo de produtores estava ocorrendo. Atualmente, a situação vincula-se a outras circunstâncias. Questiona-se quem são os que prosseguirão com a produção vitivinícola futuramente.
Além disso, o fato de o valor das terras no Vale dos Vinhedos ter sido bastante acrescido pode estimular a saída dos que não estão conseguindo acompanhar o ritmo de crescimento da região. Evidentemente, a situação não é agravante para quem está capitalizado; mesmo assim, elementos intrínsecos como tradição e cultura deveriam ser resguardados.

Nesse âmbito, positivamente, a existência de centros de ensino é extremamente importante no sentido de oferecer formação de qualidade aos jovens da região sem que eles necessitem migrar para outros lugares em busca deste conhecimento. Isso estimula um processo em que o jovem permanece na sua região e encontra espaço no mercado de trabalho nela mesmo, gerando um sentimento que valoriza o território e suas atividades econômicas. Portanto, esses centros de formação são multiplicadores de conhecimento, com relevância para a sociedade.

\subsubsection{Convenção inspirada}

No mundo da inspiração, a informação é emocional, representada por impressões artísticas e culturais. Em tal caso, o princípio é de criatividade e de inovação. Neste princípio, a ruptura de paradigmas também é apreciável.

Os imigrantes italianos receberam terras selvagens na região serrana do Rio Grande do Sul. A princípio, então, já se apresentava a dificuldade de ocupar terras de difícil acesso e impróprias para algumas atividades agrícolas. Contudo, os imigrantes foram construindo suas casas, distribuindo-se em colônias e deixando marcas de sua identidade.

A cultura também se manifestou pelo aspecto da religiosidade. Logo que os imigrantes instalaram-se na região, construíram suas casas e edificaram espaços para a prática do catolicismo, como os capitéis e capelas modestas. Além das festas paroquiais, realizavam-se os chamados filós, em que os habitantes se reuniam para rezar, festejar e realizar alguns trabalhos manuais, dispondo de comida típica, vinho e música dos corais italianos. Nessas reuniões comunitárias era 
oportuno os homens trocarem experiências sobre as práticas da agricultura.

Assim, no roteiro do Vale dos Vinhedos, apresentam-se capelas e capitéis que evidenciam a religiosidade infiltrada nos valores locais, além de existirem alguns espaços de cultura que oferecem aos visitantes a emoção de reviver os eventos dos filós tal como ocorriam outrora. Outra característica marcante é a hospitalidade, visto que as pessoas da região são reconhecidas por ser receptivas. Isso tudo influencia na personalidade da região, que é importante para a particularidade do enoturismo.

Partindo-se desse contexto, o vinho carrega um glamour composto por todos esses simbolismos. Com base nisso, os consumidores podem avaliar os produtos. O vinho é um dos poucos produtos que reúnem vários significados e que podem ser percebidos pelo consumidor.

O vinho é uma bebida prazerosa. Os italianos não só trouxeram a cultura de produzir vinho como também de degustá-lo. Embora o consumo no Brasil seja bastante baixo, até mesmo menor do que nos países vizinhos, como Uruguai e Argentina, entre os que consomem vinhos, grande parte é de descendência europeia, especialmente italiana. Nos países europeus, o vinho não é tomado simplesmente como bebida em determinadas ocasiões, mas, sim, como parte do hábito no dia a dia, distinguido como um alimento agregado às refeições. E é este ponto da cultura de consumir o vinho que os agentes da vitivinicultura desejam motivar. Com esta finalidade, frequentemente tem sido ressaltado em pesquisas o quanto é benéfico o consumo dos sucos de uva e vinhos para a saúde. Todavia, essa transformação no consumo não é uma tarefa fácil, pois procede a uma mudança cultural, logo, deve exigir algum tempo até que essa ideia seja assimilada e se transforme em acontecimento habitual na sociedade brasileira.

Em outra questão, de fato, a atividade vitivinícola como um todo é cercada por criatividade. Desde a elementar transformação da uva em vinho, até o momento de aproximar todos os simbolismos com a viagem enoturística. As viní- colas familiares que atuam no Vale dos Vinhedos antes eram somente produtores de uvas que, em um momento de crise com estoque elevado do produto que é perecível, decidiram reagir e inovar com a atividade vinícola. Até que, em outro momento futuro, chegassem a vislumbrar o reconhecimento de indicações geográficas para o seu terroir. Desse modo, observa-se que o mundo da inspiração, no que concerne à inovação, representa oportunidades de negócio; assim, a atividade enoturística também abre espaço para diversos tipos de empreendimentos, com geração de emprego e renda.

$\mathrm{O}$ enoturismo tem a propriedade de aliar todos os simbolismos e comover o público. $\mathrm{Na}$ microrregião analisada, existem museus e demais espaços que contam a história da vitivinicultura. Portanto, a atividade vitivinícola sempre foi marcada por causar a curiosidade das pessoas em conhecer mais sobre a história do vinho; logo, é nessa conjugação de fatos e fantasias que o enoturismo se insere.

\section{Considerações finais}

As vinícolas, principalmente as indústrias familiares, foram as motivadoras do projeto Vale dos Vinhedos, apresentado em um momento desfavorável e decadente para os vinhos brasileiros, quando resolveram encontrar alternativas e inovar. A delimitação da área produtora e a criação de suas indicações geográficas perpassaram esse momento. Os resultados das ações, assim, motivaram a integração entre atividades correlacionadas, compondo o enoturismo. Então, a maioria das organizações, exceto no que se refere às vinícolas, foram estabelecidas em meio a motivações de oportunidade de negócios que emergiram com a divulgação substancial que teve a microrregião após o reconhecimento da IPVV.

No âmbito institucional, a contribuição do APL vitivinícola é capaz de conferir diversos benefícios. As instituições são incisivas para o conhecimento, a pesquisa e o desenvolvimento 
da sociedade e do setor produtivo; além disso, as entidades compóem recursos de defesa dos interesses de classe e fortalecem o setor em questão. O fortalecimento da indústria vinícola deve-se, em grande parte, pela sua organização que busca apoio junto às instituições e aos governos públicos.

Enfim, observa-se que a dinâmica dos atores percorre os mundos da economia das convenções. Em cada um, inferem-se modos de agir e a correspondência entre eles, de tal forma que serve à justificação da qualidade do seu produto, expressando-se sob as diferentes dimensões. Nota-se que as relações identificamse intensamente com a coordenação do mercado, da opinião, cívica e industrial, em que se ressalta o mecanismo da indicação geográfica, por exemplo, o qual consiste, ao mesmo tempo, em instrumento de renome e qualidade, que agrega valor e que foi viabilizado pela organização dos agentes e interesse coletivo. Desse modo, pela convenção de opinião, por meio das IGs, estabelecem-se importantes ligações com os demais mundos de coordenação, fazendo convergir valores e atender interesses.

Além disso, há todo um contexto que antecede e que se reafirma, no caso, ao que concerne os fatores históricos, sociais, culturais, remetendo-se aos valores envolvidos nos mundos doméstico e inspirado, em que esses fatores são ativados e reforçados como modo de assegurar uma identidade e contribuir na avaliação e construção de um produto e seu local. Dessa forma, evidencia-se uma rede de atores, com capacidades, valores e interesses que se conjugam, que serve à qualidade do seu produto, permitindo criar um produto mais complexo, de maior valor agregado. Assim, é significativa a função das instituições, que se constituem em grandes agentes provedores do apoio, conhecimento, informação e ações necessárias para desenvolver produtos, setores e ambiente, pois a busca por excelência em qualidade e o reconhecimento desta instigou o desenvolvimento local.

Em meio às oportunidades, os negócios na microrregião atuam de forma profissional e são reconhecidos no País e até no exterior, de maneira que o Vale dos Vinhedos pode servir como exemplo de organização, inspirando outras regiões produtoras de vinho no País. Todo esse processo também contribui para desmitificar a ideia de que os vinhos brasileiros são de baixa qualidade e aumentar o consumo.

Portanto, analisou-se que a qualidade está sendo determinada endogenamente, em um processo "de baixo para cima", com influência de particularidades de seu contexto histórico, social, cultural, econômico, humano, natural e ambiental, implicando agregação de valor aos produtos e ao território. $\mathrm{O}$ resultado tem sido a identificação da qualidade dos vinhos finos e a dinâmica de um novo patamar de desenvolvimento para a microrregião. Várias dimensões precisam ser cuidadas para que se tenham efeitos positivos e sustentáveis. Todavia, não é tarefa fácil gerir todas elas e os conflitos e desafios são também produzidos nessa construção.

De todo modo, os atores estão empenhados na construção da qualidade, buscando atestar e garantir, bem como dar a conhecer a qualidade aos consumidores, conforme as ideias dos autores Tibério, Cristóvão e Fragata (2001). Então, a microrregião tem se expressadocomimagem de qualidade em vinhos, destacados pela organização e pela posse de indicações geográficas reconhecidas. E, ao lado do vinho como atrativo, converge a área geográfica com suas características peculiares, representando um potencial enoturístico.

\section{Referências bibliográficas}

ABRAMOVAY, R. Entre Deus e o diabo: mercados e interação humana nas ciências sociais. Tempo Social, São Paulo, v. 16, n. 2, p. 35-64, nov. 2004.

BARREY, S. e VALCESCHINI, E. Les problématiques de la qualité dans l'agroalimentaire: bilan et perspectives. GRD Economie \& Sociologie, Montpelier, p. 23-40, mar. 2006.

BOLTANSKI, L. e THÉVENOT, L. De la justification: les économies de la grandeur. Paris: Gallimard, 1991. 
DENZIN, N. K. e LINCOLN, Y.S. (Orgs.). O planejamento da pesquisa qualitativa: teorias e abordagens. Porto Alegre: Artmed, 2006.

EYMARD-DUVERNAY, M. F. e FAVEREAU, O. Les conventions dans la vie économique. In: SÉMINAIRE VIE DES AFFAIRES, 1996, Paris. Actes... Paris: l'École de Paris, 1996. 10 p.

EYMARD-DUVERNAY,M.F;FAVEREAU,O.;ORLÉAN, A.; SALAIS, R. e THÉVENOT, L. Valeurs, Coordination et Rationalité: l'economie des conventions ou le temps de la reunification dans les sciences economiques, sociales et politiques. In: EYMARD-DUVERNAY, M. F. (Ed.). Problèmes Économiques, Paris, oct. 2003. p. 23-44.

FÁVERO, K. C. Indicação Geográfica. In: PIMENTEL, L.O. (Org.). Curso de propriedade intelectual e inovação no agronegócio. 2 ed. Brasília: MAPA; Florianópolis: UFSC, 2010. p. 240-253.

FLEXOR, G. Os alimentos de qualidade específica entre contratos e convenção. In: CONGRESSO DA SOCIEDADE BRASILEIRA DE ECONOMIA, ADMINISTRAÇÃO E SOCIOLOGIA RURAL, 43., 2005, Ribeirão Preto. Anais... Ribeirão Preto: USP, 2005. 13 p.

GIL, A. C. Métodos e Técnicas de Pesquisa Social. 5. ed. São Paulo: Atlas, 2007.

HOCQUETTE, J. F. e GIGLI, S. The challenge of quality. In: . Indicators of milk and beef quality. Wageningen: Wageningen Academic Publishers, 2005. p. 13-22.

PONTE, S. e GIBBON, P. Quality standards, conventions and the governance of global value chains. Economy and Society, London, v. 34, n. 1, p. 1-31, febr. 2005.

RENARD, M. C. Fair trade: quality, market and conventions. Journal of Rural Studies, Oxford, v. 19, n. 1, p. $87-96,2003$.

SCHERER-WARREN, I. Ações coletivas na sociedade contemporânea e o paradigma das redes. Sociedade e Estado, Brasília, v. 13, n. 1, p. 55-70, 1998.
SWEDBERG, R. Economic sociology: today and tomorrow. Tempo Social, São Paulo, v. 16, n. 2, p. 7-34, nov. 2004.

THÉVENOT, L. Justification et compromis. In: CANTO-SPERBER, M. (Ed.). Dictionnaire d'éthique et de philosophie morale. Paris: PUF, 1996. p. 789-794.

TIBÉRIO, M. L.; CRISTÓVÃO, A. e FRAGATA, A. Produtos Tradicionais e Construção da Qualidade: $\mathrm{O}$ caso das designações protegidas Salpicão de Vinhais e Linguiça de Vinhais IGP. In: COLÓQUIO HISPANO-PORTUGUÉS DE ESTÚDIOS RURALES DE LA PENÍNSULA IBÉRICA, 4., 2001, Santiago de Compostela. Anais... Santiago de Compostela: AEEA, SPER, IDEGA, 2001. 27 p.

TRIVIÑOS, A. N. S. Introdução à pesquisa em ciências sociais. São Paulo: Atlas, 1990.

TROMBIN, V. G.; CALDEIRA, M. A. e NEVES, M. F. Criando marcas regionais (Indicação Geográfica). In: NEVES, M. F (Org.). Agronegócios e desenvolvimento sustentável: uma agenda para a liderança mundial na produção de alimentos e bionergia. São Paulo: Atlas, 2007.

VALDUGA, V. O processo de desenvolvimento do enoturismo no Vale dos Vinhedos. 2007. 151 f. Dissertação (Mestrado em Turismo) - Programa de Pós-Graduação em Turismo, Universidade de Caxias do Sul, Caxias do Sul, 2007.

WILKINSON, J. Sociologia econômica, a teoria das convenções e o funcionamento dos mercados: inputs para analisar os micros e pequenos empreendimentos agroindustriais no Brasil. Ensaios FEE, Porto Alegre, v. 23, n. 2, p. 805-824, 2002.

ZYLBERSZTAJN, D. e SCARE, R. F. Gestão da qualidade no Agribusiness: estudos e casos. São Paulo: Atlas, 2003. 
